\title{
The role of mineral and organic components in phenanthrene and dibenzofuran sorption by soil
}

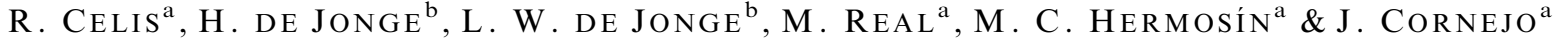 \\ ${ }^{a}$ Instituto de Recursos Naturales y Agrobiología de Sevilla, CSIC, Avda Reina Mercedes 10, PO Box 1052, 41080 Sevilla, Spain, and \\ ${ }^{\mathrm{b}}$ Danish Institute of Agricultural Sciences, Department of Agroecology, Research Centre Foulum, PO Box 50, 8830 Tjele, Denmark
}

\begin{abstract}
Summary
Improved predictions of sorption of hydrophobic organic compounds (HOCs) in soil require a better knowledge of the relative contribution of inorganic and organic soil constituents to the sorption process. In this paper, sorption of a three-ring polycyclic aromatic hydrocarbon (phenanthrene) and a three-ring heterocyclic-aromatic compound (dibenzofuran) by six agricultural soils, their clay-size fractions, and a series of single, binary, and ternary model sorbents was evaluated to elucidate the relative role of soil mineral and organic components in the retention of these two model HOCs. The sorption coefficients for

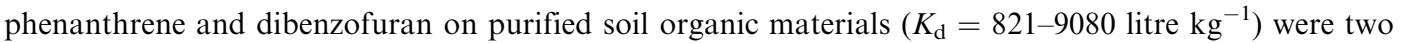
orders of magnitude greater than those measured on mineral model sorbents $\left(K_{\mathrm{d}}=0-114\right.$ litre $\left.\mathrm{kg}^{-1}\right)$. This, along with the strong correlation between sorption and the organic $\mathrm{C}$ content of the soil clay fractions $(r=0.99, P<0.01)$, indicated a primary role of soil organic matter in the retention of both compounds. However, weak relationships between phenanthrene and dibenzofuran sorption coefficients and the organic $\mathrm{C}$ content of the bulk soils and variability of $K_{\mathrm{oc}}$ values among soils, clay fractions, and model sorbents (1340-21020 litre $\mathrm{kg}^{-1} \mathrm{C}$ for phenanthrene and 1685-7620 litre $\mathrm{kg}^{-1} \mathrm{C}$ for dibenzofuran) showed that sorption was not predictable exclusively from the organic $\mathrm{C}$ content of the materials. Organic matter heterogeneity and domain blockage arising from organic matter-clay interactions and associated $\mathrm{pH}$ shifts were identified as the most likely causes of the different organic C-normalized sorption capacities of the soils. A direct contribution from minerals to the sorption of phenanthrene and dibenzofuran by the soils studied was likely to be small. Our results suggested that suitable descriptors for the extent of organic matter-mineral interactions would help to improve current $K_{\mathrm{oc}}$-based sorption predictions and subsequently the assessment of risk associated with the presence of HOCs in soil.
\end{abstract}

\section{Introduction}

Sorption is considered one of the principal processes determining the bioavailability and movement of organic contaminants in the environment. Modelling the fate and transport of organic contaminants in soil and water systems requires quantitative estimates of sorption. Tools for ranking contaminated sites according to risks and prioritization of clean-up measures for brown-field redevelopment are also based on sorption predictions. Since one of the keys for understanding sorption and aging processes is the composition of the soil matrix, much effort has been devoted to relate sorption to the soil composition. For very hydrophobic organic compounds (HOCs), research over the last three decades has stressed the primary role of soil organic matter (SOM) in the sorption process, primarily because inorganic constituents are normally hydrated and sorption of HOCs by SOM predominates over

Correspondence: R. Celis. E-mail: rcelis@irnase.csic.es

Received 12 October 2004; revised version accepted 14 April 2005 sorption to minerals (Hamaker \& Thompson, 1972; Carmo et al., 2000; Wauchope et al., 2002). Accordingly, a common approach to describe and predict the partitioning of HOCs between the soil's solid and solution phases has been to take the product of an organic C-normalized distribution coefficient, $K_{\mathrm{oc}}$, and the mass fraction of organic $\mathrm{C}$ in the soil (Hamaker \& Thompson, 1972; Karickhoff, 1984; Njoroge et al., 1998).

Although the variability of $K_{\mathrm{oc}}$ values among soils with different physicochemical characteristics has been found to be large, the temptation to regard $K_{\mathrm{oc}}$ as a universal constant, independent of soil type, has been strong (Wauchope et al., 2002). Recently, the increasing development of models to assess the impact of HOCs in the environment has intensified demand for more accurate sorption predictions. Consequently, achieving a better understanding of the causes of the wide variation in experimental values and correlations for the parameter $K_{\mathrm{oc}}$ is considered an important research goal (Jones \& Tiller, 1999). 
Research over the last decade has revealed that organic matter heterogeneity, solution chemistry, and the contribution of inorganic constituents to the sorption process are among the most important causes of the variability of $K_{\mathrm{oc}}$. Thus, it has been suggested that the binding coefficient of SOM might be influenced by properties such as its aromaticity, polarity, structure or configuration, and abundance of certain functional groups (Laor et al., 1998; Wauchope et al., 2002; Huang et al., 2003). Some of these characteristics, like SOM polarity or conformation, have been shown to vary with the solution chemistry, in particular with $\mathrm{pH}$, ionic strength, and soil solution cation composition (Schlautman \& Morgan, 1993; Njoroge et al., 1998; Jones \& Tiller, 1999). Considerable effort is currently directed to relate measurable indexes of SOM characteristics to its sorptivity towards different classes of HOCs (Njoroge et al., 1998; Karapanagioti et al., 2000; Ahmad et al., 2001).

While there is a general consensus that organic matter characteristics can greatly influence its affinity for HOCs, the contribution of the inorganic fraction to the varied organic C-normalized sorption capacities of soils remains less well understood. Recent findings showing that very hydrophobic organic chemicals are able to interact extensively with certain clay minerals appear to be in conflict with the classical idea that, except for systems with very small organic $\mathrm{C}$ contents $(<1 \%)$, the sorption of HOCs is independent of mineral type and content. As an example, Hundal et al. (2001) reported that the sorption capacities of some reference smectites for phenanthrene are comparable to those of natural soil clays containing substantial amounts of organic $\mathrm{C}(>4 \%)$.

Another potential effect of soil minerals, in particular those included in the clay-size fraction, is related to their ability to associate with SOM. Mineral-SOM interactions can influence the sorption capacity of SOM by direct blockage of domains involved in the sorption of HOCs or by inducing conformational changes leading to increased or decreased accessibility for HOCs (Pusino et al., 1992; Njoroge et al., 1998; Laor et al., 1998; Jones \& Tiller, 1999). Because the consequences of interactions of SOM with soil minerals on HOC sorption are not fully understood, identification of these interactions and determination of how they can be represented in future models have been stressed as important in improving sorption predictions (Celis et al., 1998; Njoroge et al., 1998; Jones \& Tiller, 1999).

The present study was designed to provide further insight into the relative contribution of inorganic and organic components of soil in the retention of HOCs. For this purpose, the sorption of two model HOCs (phenanthrene and dibenzofuran) by six agricultural soils differing in organic $\mathrm{C}$ and clay contents, their clay-size fractions, and a series of single, binary, and ternary model sorbents was evaluated, and relationships between sorption and sorbent characteristics were established. The use of well-characterized binary and ternary model particles of three active soil constituents (montmorillonite, ferrihydrite, and humic acid) allowed us to draw some conclusions concerning the effects of soil-mineral association on the sorption of HOCs and to illustrate the need to represent this association to improve sorption predictions.

\section{Materials and methods}

\section{Chemicals}

Dibenzofuran $\left(\mathrm{C}_{12} \mathrm{H}_{8} \mathrm{O}\right)$ is a three-ring heterocyclic, aromatic compound of molecular weight $168 \mathrm{~g} \mathrm{~mol}^{-1}$ and water solubility about $5 \mathrm{mg} \mathrm{litre} \mathrm{e}^{-1}$ at $25^{\circ} \mathrm{C}$. Dibenzofuran of purity $>99 \%$, purchased from Sigma (Germany), was used in this study. Phenanthrene $\left(\mathrm{C}_{14} \mathrm{H}_{10}\right)$ is a three-ring, polycyclic, aromatic hydrocarbon of molecular weight $178 \mathrm{~g} \mathrm{~mol}^{-1}$ and water solubility about $1.2 \mathrm{mg} \mathrm{l}^{-1}$ at $25^{\circ} \mathrm{C}$. Phenanthrene of purity $>98 \%$ was purchased from Aldrich Chemical Company, Inc. (Milwaukee, WI). Ring-UL- ${ }^{14} \mathrm{C}$-phenanthrene (specific activity $=55 \mathrm{mCi} \mathrm{mmol}^{-1}$; radiochemical purity $\geq 99 \%$ ) was purchased from American Radiolabeled Chemicals Inc. (St Louis, MO). The chemical structures of phenanthrene and dibenzofuran are shown in Figure 1.

\section{Soils}

Six agricultural soils differing in their physicochemical properties were selected for this study (Table 1). The soils were sampled from the top 0-20 cm layer, air-dried, and passed through a 2-mm aperture sieve before the experiments. Standard particle-size determination was performed by hydrometer and sieve analysis (Gee \& Bauder, 1982). Soil pH was measured in a 1:2.5 (w:w) soil:0.01 $\mathrm{M} \mathrm{CaCl}_{2}$ suspension. Total $\mathrm{C}$ was determined in a Leco $1000 \mathrm{CNS}$ analyzer after combustion at $1650^{\circ} \mathrm{C}$ and subsequent infrared detection of $\mathrm{CO}_{2}$ (Tabatabai \& Bremner, 1970). Inorganic $\mathrm{C}$ was measured from the volume of $\mathrm{CO}_{2}$ collected in a Scheibler apparatus, after addition of $10 \% \mathrm{HCl}$ to $10 \mathrm{~g}$ of soil. The organic C content was calculated from the difference between total $\mathrm{C}$ and inorganic $\mathrm{C}$. The cation exchange capacity (CEC) of the soils was determined by saturation with ammonium acetate, according to Rhoades (1982). Soil specific surface areas (SSA) were estimated by the EGME method, omitting pretreatments to remove organic matter and saturation with $\mathrm{Ca}^{2+}$ (Cihacek \& Bremner, 1979), and also by nitrogen adsorption at $77 \mathrm{~K}$

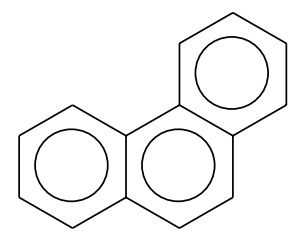

Phenanthrene
Dibenzofuran

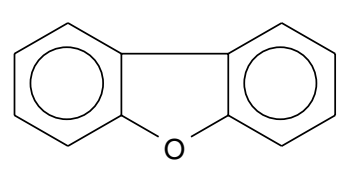

Figure 1 The molecular structures of phenanthrene and dibenzofuran. 
Table 1 Physicochemical characteristics of the soils studied

\begin{tabular}{|c|c|c|c|c|c|c|}
\hline Soil property & $\mathrm{P} 2$ & Flakkebjerg & Askov & Borris & IFA & Kettering \\
\hline Country of origin & Spain & Denmark & Denmark & Denmark & Austria & UK \\
\hline Soil texture ${ }^{a}$ & SCL & $\mathrm{L}$ & SL & SL & $\mathrm{L}$ & SCL \\
\hline Sand $^{\mathrm{b}} / \%$ & 68.4 & 41.6 & 68.4 & 69.8 & 31.0 & 47.2 \\
\hline $\mathrm{Silt}^{\mathrm{b}} / \%$ & 10.4 & 36.1 & 18.8 & 20.5 & 36.1 & 24.7 \\
\hline Clay $^{\mathrm{b}} / \%$ & 20.3 & 20.2 & 10.4 & 6.9 & 24.7 & 24.5 \\
\hline Inorganic $\mathrm{C} / \%$ & $<0.1$ & $\mathrm{ND}^{\mathrm{c}}$ & ND & ND & 0.61 & $<0.1$ \\
\hline Organic $\mathrm{C} / \%$ & 0.56 & 1.25 & 1.39 & 1.67 & 1.84 & 2.09 \\
\hline Organic $\mathrm{C} /$ clay ratio & $1: 36$ & $1: 16$ & $1: 7$ & $1: 4$ & $1: 13$ & $1: 12$ \\
\hline $\mathrm{CEC}^{\mathrm{d}}\left(\mathrm{Na}^{+}\right) / \mathrm{cmol}_{\mathrm{c}} \mathrm{kg}^{-1}$ & 0.11 & 0.27 & 0.12 & 0.17 & 17.4 & 0.11 \\
\hline $\operatorname{CEC}\left(\mathrm{K}^{+}\right) / \mathrm{cmol}_{\mathrm{c}} \mathrm{kg}^{-1}$ & 0.48 & 0.39 & 0.30 & 0.30 & ND & 0.29 \\
\hline $\operatorname{CEC}\left(\mathrm{Mg}^{2+}\right) / \mathrm{cmol}_{\mathrm{c}} \mathrm{kg}^{-1}$ & 2.82 & 0.69 & 0.48 & 0.51 & ND & 0.95 \\
\hline $\mathrm{CEC}\left(\mathrm{Ca}^{2+}\right) / \mathrm{cmol}_{\mathrm{c}} \mathrm{kg}^{-1}$ & 19.5 & 16.5 & 9.7 & 10.8 & ND & 17.8 \\
\hline $\mathrm{CEC}$ (total) $/ \mathrm{cmol}_{\mathrm{c}} \mathrm{kg}^{-1}$ & 22.8 & 17.8 & 10.6 & 11.8 & 17.4 & 19.2 \\
\hline $\mathrm{pH}$ & 7.3 & 7.1 & 6.3 & 6.4 & 7.7 & 6.7 \\
\hline EGME-SSA $^{\mathrm{e}} / \mathrm{m}^{2} \mathrm{~g}^{-1}$ & 19.3 & 37.0 & 17.4 & 10.4 & 39.1 & 52.3 \\
\hline $\mathrm{N}_{2}-\mathrm{SSA}^{\mathrm{f}} / \mathrm{m}^{2} \mathrm{~g}^{-1}$ & 19.5 & 8.8 & 5.3 & 4.4 & 18.1 & 18.5 \\
\hline$\Delta \mathrm{N}_{2}-\mathrm{SSA}^{\mathrm{g}} / \mathrm{m}^{2} \mathrm{~g}^{-1}$ & - & 3.0 & 3.7 & 0 & 3.9 & 14.9 \\
\hline
\end{tabular}

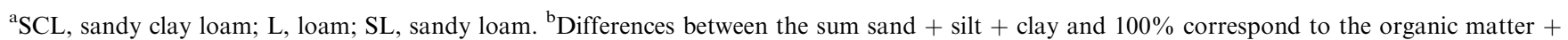
carbonate content of the soils. ${ }^{\mathrm{c}} \mathrm{ND}$, not detected. ${ }^{\mathrm{d}} \mathrm{CEC}$, cation exchange capacity. ${ }^{\mathrm{e}} \mathrm{EGME-SSA}$, specific surface area measured by ethyleneglycolmonomethylether retention. ${ }^{\mathrm{f}} \mathrm{N}_{2}$-SSA, specific surface area measured by nitrogen adsorption. ${ }^{\mathrm{g}} \Delta \mathrm{N}_{2}-\mathrm{SSA}$, increase in $\mathrm{N}_{2}$-SSA of the soils after calcination at $350^{\circ} \mathrm{C}$.

using a Carlo Erba Sorptomatic 1990 (Fisons Instruments, Milan). The soil samples were degassed at $80^{\circ} \mathrm{C}$ and equilibrated under vacuum for 15 hours before measuring the $\mathrm{N}_{2}$ adsorption isotherm. Nitrogen-SSA values were calculated for uncalcined and calcined $\left(350^{\circ} \mathrm{C}\right.$, overnight) soil samples by applying the BET method to the $\mathrm{N}_{2}$ adsorption data between relative pressures of 0.02 and 0.25 .

\section{Clay fractions}

The clay fraction $(<2 \mu \mathrm{m}$ particle-size fraction) of the Borris, Askov, Kettering, and P2 soils was separated by sedimentation using the pipette method after carbonate elimination (Jackson, 1975). Once extracted, the clay fractions were saturated with $\mathrm{Ca}^{2+}$ by three successive treatments with $0.5 \mathrm{M} \mathrm{CaCl}_{2}$, and then washed with deionized water until $\mathrm{Cl}$-free and freezedried. Elemental analysis of the soil clays was carried out in a Perkin-Elmer, model 1106, elemental analyzer (Perkin-Elmer Corp., Norwalk, CT). The silicate-clay mineralogy was determined semiquantitatively by $\mathrm{X}$-ray diffraction analysis on oriented specimens of $\mathrm{Mg}^{2+}$ - and $\mathrm{K}^{+}$-saturated samples treated with ethyleneglycol and calcined at $500^{\circ} \mathrm{C}$, respectively (Brown, 1961). Specific surface areas of the soil clay samples were determined by $\mathrm{N}_{2}$ adsorption as described above.

\section{Model sorbents}

The organic soil materials (Table 5) were selected for having a large organic matter content and small clay and carbonate contents. Samples were collected from organic surface layers under aerobic $\left(\mathrm{O}_{\mathrm{h}}\right)$ or anaerobic $(\mathrm{H})$ conditions, and from an illuvial organic horizon $\left(\mathrm{B}_{\mathrm{hs}}\right)$. The $\mathrm{O}_{\mathrm{h}} \mathrm{S}, \mathrm{O}_{\mathrm{h}} \mathrm{F}$, and $\mathrm{O}_{\mathrm{h}} \mathrm{P}$ samples were taken from the wettest horizons of the organic topsoil in a spruce, Douglas fir, and Scots pine forest at Veluwe (the Netherlands). The $B_{h s}$ sample was collected at a depth of $60 \mathrm{~cm}$ in a Carbic Podzol near Veghel (the Netherlands), whereas the peat sample $(\mathrm{H})$ was collected from a Histosol near Pesse (the Netherlands). All organic materials were dried at $50^{\circ} \mathrm{C}$ for 72 hours and ground to pass through a $2-\mathrm{mm}$ aperture sieve before further use, except the $\mathrm{O}_{\mathrm{h}} \mathrm{P}$ sample, which was passed through a $1-\mathrm{mm}$ aperture sieve. The humic acid fractions, HA1 and HA2, were prepared from commercially available humic acid (Aldrich H1, 675-2) and the A horizon $(0-15 \mathrm{~cm})$ of a Histosol, respectively. The commercial humic acid (HA1) was dissolved in demineralized water (1:50 $\mathrm{w}: \mathrm{w})$, brought to $\mathrm{pH} 2.0$ with $0.1 \mathrm{M} \mathrm{HCl}$, and allowed to settle for 24 hours. The precipitate was washed twice with $0.5 \mathrm{M}$ and $0.01 \mathrm{M} \mathrm{CaCl}_{2}$, respectively, in order to obtain the insoluble humate, and then freeze-dried. The soil humic acid (HA2) was extracted with $0.5 \mathrm{M} \mathrm{NaOH}$, precipitated with $6 \mathrm{M} \mathrm{HCl}$, washed with $0.1 \mathrm{M} \mathrm{HCl}$ and $0.3 \mathrm{M} \mathrm{HF}$ and then with distilled water, dialysed (molecular weight cutoff: $3.5 \mathrm{kDa}$ ) and freezedried.

Single, binary, and ternary model sorbents containing SWy-2 Wyoming montmorillonite (SW), poorly crystallized ferrihydrite, and soil-extracted humic acid (HA2) were prepared according to Cruz-Guzmán et al. (2003). In brief, SW-ferrihydrite binary associations were prepared by neutralizing with $0.1 \mathrm{M} \mathrm{NaOH}$ 
(final $\mathrm{pH}=7.5$ ) suspensions containing $500 \mathrm{ml}$ of $\mathrm{Fe}\left(\mathrm{NO}_{3}\right)_{3} 15$ or $30 \mathrm{mM}$ and $10 \mathrm{~g}$ of SW. The resulting SW-ferrihydrite complexes were shaken for 16 hours, washed with deionized water until $\mathrm{NO}_{3}{ }^{-}$-free and finally freeze-dried. SW-HA2 and ferrihydrite-HA2 binary associations were prepared by shaking suspensions containing $400 \mathrm{ml}$ of a dissolved HA2 solution (1 or $2 \mathrm{~g}$ litre $\left.{ }^{-1}, \mathrm{pH} 6.5\right)$ and $10 \mathrm{~g}$ of either SW or freshly precipitated ferrihydrite for 16 hours. After shaking, the suspensions were dialysed against distilled water and freeze-dried. Finally, SWferrihydrite-HA2 ternary particles were obtained by shaking $10 \mathrm{~g}$ of freshly precipitated SW-ferrihydrite binary complex in $400 \mathrm{ml}$ of the dissolved HA2, then dialysing and freeze-drying.

\section{Sorption by soils}

Phenanthrene and dibenzofuran sorption isotherms on soils were obtained by the batch equilibration procedure using glass centrifuge tubes closed with Teflon caps. Triplicate soil aliquots $(0.2 \mathrm{~g}$ for phenanthrene and $0.5 \mathrm{~g}$ for dibenzofuran) were equilibrated with $10 \mathrm{ml}$ of aqueous solutions of phenanthrene or dibenzofuran by gently rotating in an end-over-end shaker (30 r.p.m.) at $20 \pm 2^{\circ} \mathrm{C}$ for 24 hours. A preliminary kinetic experiment showed that apparent equilibrium was reached within 24 hours. Initial dibenzofuran solutions (5, 10,15 , and $20 \mu \mathrm{M}$ ) were prepared in $10 \mathrm{mM} \mathrm{CaCl}_{2}$ from a stock $10 \mathrm{~mm}$ dibenzofuran solution prepared in acetone. The amount of acetone in the initial dibenzofuran solutions was therefore $<0.2 \%$. Initial phenanthrene solutions $(0.002,0.02$, $0.2,2.0$, and $3.5 \mu \mathrm{M}$ ) were prepared in $3 \mathrm{mM} \mathrm{CaCl}_{2}$ by mixing labelled and non-labelled phenanthrene. The ${ }^{14} \mathrm{C}$ activity of the initial phenanthrene solutions ranged between 22.8 and $45.7 \times 10^{3} \mathrm{~Bq}$ litre $^{-1}$. After equilibration, the suspensions were centrifuged at $5420 \mathrm{~g}$ for 1 hour, and then $3 \mathrm{ml}$ of the supernatant solution was removed for analysis (see below) using a glass pipette. The amount of phenanthrene and dibenzofuran sorbed was calculated by difference between the initial and final solution concentrations. Initial solutions without soil were also shaken for 24 hours and served as controls. Sorption isotherms were fitted to the Freundlich equation: $C_{\mathrm{s}}=K_{\mathrm{f}} C_{\mathrm{eq}}{ }^{\mathrm{n}}$, where $C_{\mathrm{s}}\left(\mu \mathrm{mol} \mathrm{kg}{ }^{-1}\right)$ is the amount of chemical sorbed at the equilibrium concentration $C_{\mathrm{eq}}\left(\mu \mathrm{mol}\right.$ litre $^{-1}$ ), and $n$ (unitless) and $K_{\mathrm{f}}\left(\mu \mathrm{mol}^{1-n} \operatorname{litre}^{n} \mathrm{~kg}^{-1}\right)$ are the empirical Freundlich constants, which can be calculated from the linear plot of $\log C_{\mathrm{s}}$ against $\log C_{\text {eq }}$. Distribution coefficients, $K_{\mathrm{d}}$ (litre $\mathrm{kg}^{-1}$ ), were also calculated for each soil at an initial concentration of $2 \mu \mathrm{M}$ (phenanthrene) or $10 \mu \mathrm{M}$ (dibenzofuran) by dividing the amount of chemical sorbed, $C_{\mathrm{s}}\left(\mu \mathrm{mol} \mathrm{kg} \mathrm{kg}^{-1}\right)$, by the equilibrium solution concentration, $C_{\mathrm{eq}}\left(\mu \mathrm{mol}\right.$ litre $\left.^{-1}\right)$. These initial concentrations were selected to achieve about $30 \%$ of the water solubility of the compounds. Organic C-normalized distribution coefficients, $K_{\text {d-oc }}\left(\right.$ litre $\mathrm{kg}^{-1} \mathrm{C}$ ), were calculated by dividing the $K_{\mathrm{d}}$ values by the fractional organic $\mathrm{C}$ content of the soils.

\section{Sorption by soil clay fractions and model sorbents}

Sorption of phenanthrene and dibenzofuran by soil clay fractions and model sorbents was determined at a single initial concentration by equilibrating ( 24 hours) $50 \mathrm{mg}$ of sorbent with $10 \mathrm{ml}$ of phenanthrene $(2 \mu \mathrm{M})$ or dibenzofuran $(10 \mu \mathrm{M})$ initial solution. For highly sorptive organic materials (i.e. Oh, $\mathrm{H}$, and HA samples) smaller amounts of sorbent $(10 \mathrm{mg})$ were used. After equilibration, the suspensions were centrifuged at $5420 \mathrm{~g}$ for 1 hour and the concentration of phenanthrene and dibenzofuran in the supernatant was determined as described below. Sorption distribution coefficients, $K_{\mathrm{d}}\left(\right.$ litre $\mathrm{kg}^{-1}$ ), were calculated for each sorbent by dividing the amount of chemical sorbed, $C_{\mathrm{s}}\left(\mu \mathrm{mol} \mathrm{kg}{ }^{-1}\right)$, by the equilibrium solution concentration, $C_{\text {eq }}\left(\mu \mathrm{mol}\right.$ litre $\left.^{-1}\right)$.

\section{Analysis}

Dibenzofuran was determined by high performance liquid chromatography (HPLC) (Waters 600E chromatograph coupled to a Waters 996 diode-array detector). The following chromatographic conditions were used: Novapack C18 column (150 mm length $\times 3.9 \mathrm{~mm}$ internal diameter) (Waters), acetonitrile:water (70:30) eluent mixture at a flow rate of $1 \mathrm{ml}$ minute $^{-1}$, $25 \mu \mathrm{l}$ injection volume, and UV detector at $280 \mathrm{~nm}$. External calibration curves with standard solutions of dibenzofuran between 1 and $20 \mu \mathrm{M}$ were used in the calculations. Phenanthrene concentrations were determined by liquid scintillation counting (Packard $2250 \mathrm{CA}$, Downers Grove, IL) by mixing $3 \mathrm{ml}$ of solution with $17 \mathrm{ml}$ of Ultima Gold scintillation cocktail (Packard, Downers Grove, IL). Radioactivity measurements were transformed to concentration values using the ${ }^{14} \mathrm{C}$ activity of the initial phenanthrene solutions. The limits of detection for the analytical methods used in this work were $0.1 \mu \mathrm{M}$ for dibenzofuran and $10^{-4} \mu \mathrm{M}$ for phenanthrene.

\section{Results}

\section{Soil characterization}

Results of the soil characterization are summarized in Table 1. The $\mathrm{pH}$ of the Askov, Borris, and Kettering soils was neutral to slightly acid with values in the range 6-7 (Table 1). Flakkebjerg, IFA, and P2 soils were neutral to slightly basic, with $\mathrm{pH}$ in the range 7-8. All the soils studied were agricultural soils, so that the $\mathrm{pH}$ could have been influenced over past decades by agricultural practices, such as liming. Nevertheless, appreciable levels of carbonates were found in the Austrian IFA soil only (Table 1), which is in accordance with the high $\mathrm{pH}$ of this soil. The organic $\mathrm{C}$ content of the soils ranged between $0.56 \%$ (P2 soil, Spain) and 2.09\% (Kettering soil, UK). The small organic C content of the Spanish P2 soil is a common feature of soils from Mediterranean regions, and determines important physicochemical characteristics of 
those soils. Excluding the P2 soil, there was a relatively small

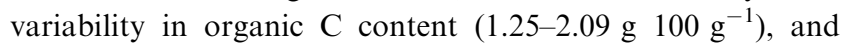
hence the variation of the CEC and SSA was mainly explained by the variation in the clay content. Indeed, the clay content

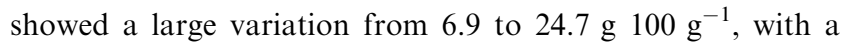
standard deviation of $47.4 \%$ of the mean, and was highly correlated with the CEC $(r=0.94, P<0.05), \mathrm{N}_{2}$-SSA $(r=0.92, P<0.05)$, and EGME-SSA $(r=0.96, P<0.01)$.

\section{Sorption by soils}

Phenanthrene and dibenzofuran sorption isotherms on soils (Figure 2) were well described by the Freundlich equation, with regression coefficients $R^{2}>0.99$. Dibenzofuran sorption isotherms were L-type ( $n=0.67-0.86)$ according to the Giles et al. (1960) classification, whereas a greater degree of linearity ( $n=0.89-0.95)$ was observed for phenanthrene sorption (Table 2). The $n$ values measured for dibenzofuran are within the range of 0.58-0.86 reported by Broholm et al. (1999) for the sorption of this compound on clayey till samples. The greater linearity of phenanthrene sorption isotherms, frequently related to partitioning into SOM (Chiou et al., 1979; Onken \& Traina, 1997; Carmo et al., 2000), can be attributed to both the greater hydrophobicity of this compound (Figure 1) and the smaller concentrations used in phenanthrene sorption experiments compared with dibenzofuran (Celis et al., 1997).

Correlation analyses were performed between sorption coefficients, $K_{\mathrm{d}}$, calculated at single initial concentrations $\left(C_{\mathrm{ini}}=\right.$ $2 \mu \mathrm{M}$ for phenanthrene and $C_{\mathrm{ini}}=10 \mu \mathrm{M}$ for dibenzofuran), and relevant physicochemical soil properties (Table 3).
Considering all six soils, it was difficult to relate the sorption coefficients to the soil composition. The only statistically significant correlation $(P<0.05)$ was found between phenanthrene sorption and soil $\mathrm{pH}$ (Table 3, Figure 3). For both phenanthrene and dibenzofuran, $K_{\mathrm{d}}$ values were weakly positively related to the organic $\mathrm{C}$ content and inversely related to the clay content. Inverse relationships were also found between $K_{\mathrm{d}}$ and CEC, $\mathrm{N}_{2}$-SSA, and EGME-SSA, probably because these soil properties were correlated with the clay content. These results suggest that several factors, including a positive effect of organic $\mathrm{C}$ and a negative effect of clay, could have simultaneously influenced the sorption of phenanthrene and dibenzofuran by the soils. In fact, a multivariate analysis showed that the multiple correlation coefficient between sorption and the organic $\mathrm{C}$ and clay content of the soils was 0.91 $(P=0.07)$ for both phenanthrene and dibenzofuran. Similarly, considering only the P2, Flakkebjerg, Askov, and Borris soils, where the increase in organic $\mathrm{C}$ content was accompanied by a decrease in clay content, phenanthrene and dibenzofuran sorption were strongly correlated with the organic C content $(r=0.98, P=0.01$ for both phenanthrene and dibenzofuran).

Figure 2 shows that at similar equilibrium concentrations phenanthrene was sorbed by all soils to a greater extent than dibenzofuran, which can be attributed to the solubility difference between the two compounds (Xing, 2001). Despite the different soil-to-solution ratios and different spiking concentrations used for phenanthrene and dibenzofuran, a very strong correlation $(r=0.98, P<0.001)$ was found between the $K_{\mathrm{d}}$ values measured for phenanthrene and those measured for dibenzofuran, indicating that soil characteristics influenced
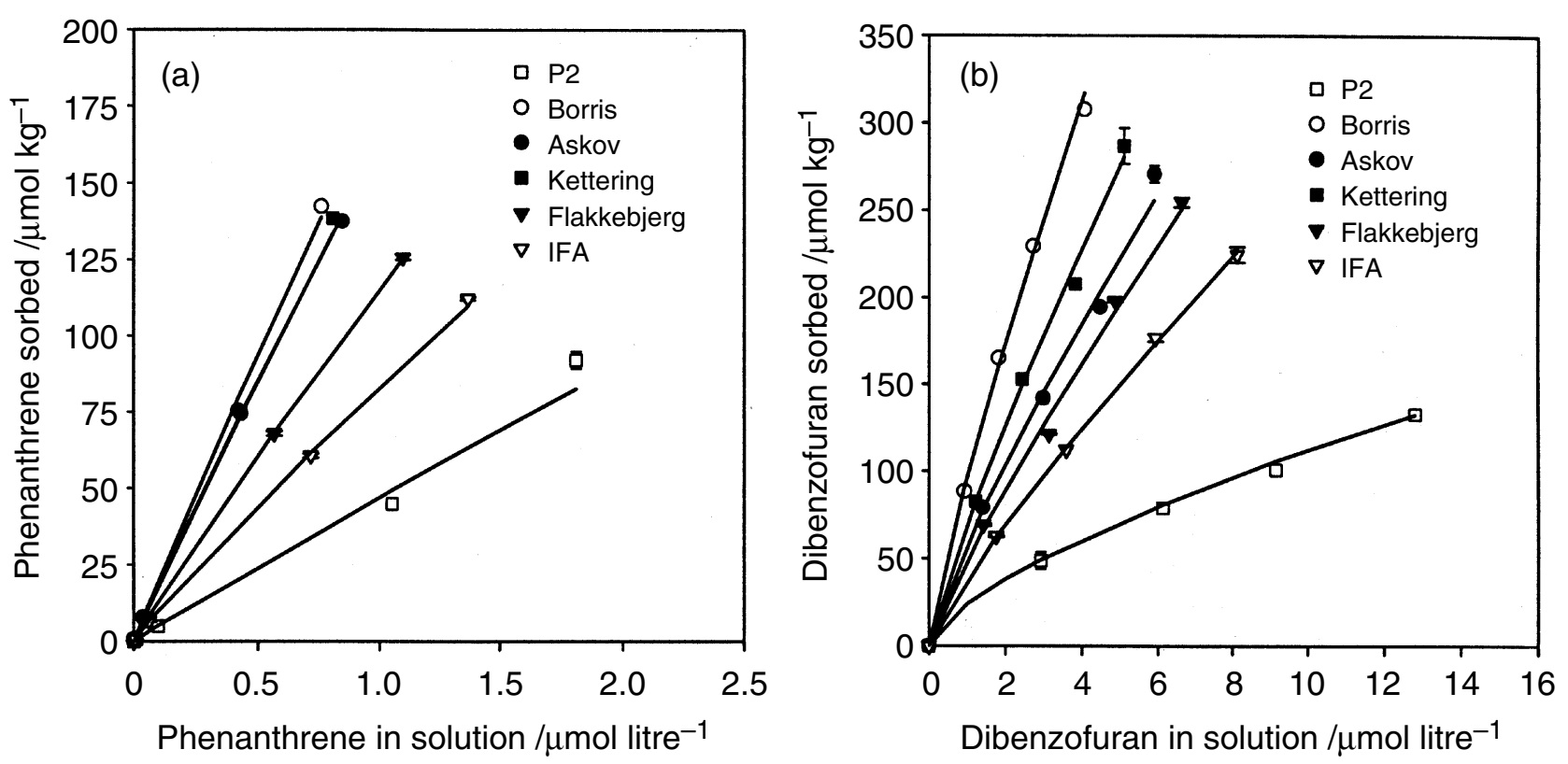

Figure 2 Phenanthrene (a) and dibenzofuran (b) sorption isotherms on soil samples. Symbols are experimental data points and lines are the Freundlich-fit sorption isotherms. 


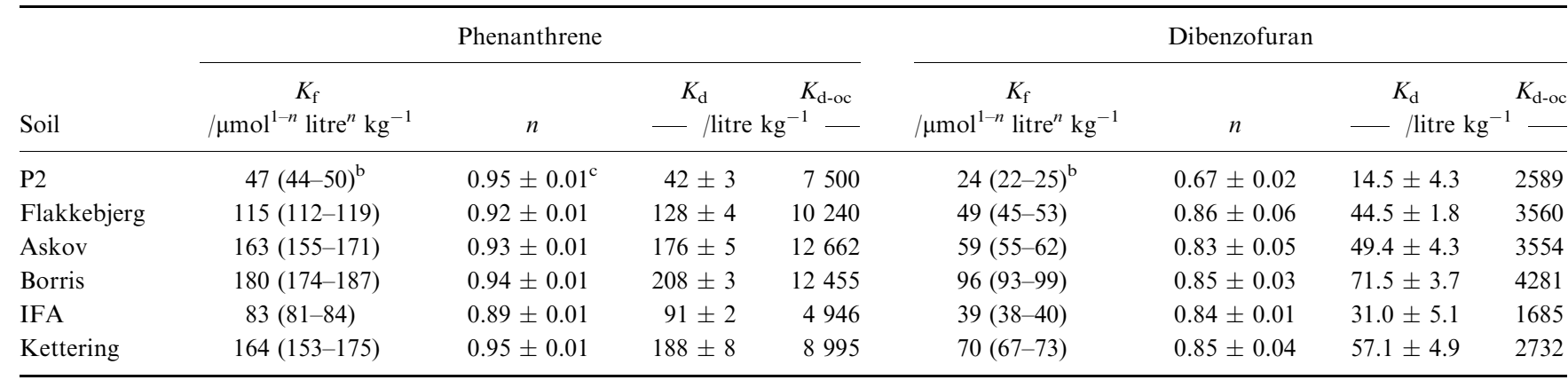

${ }^{\mathrm{a}} K_{\mathrm{f}}$ and $n$ are the Freundlich constants, whereas $K_{\mathrm{d}}$ and $K_{\mathrm{d}-\mathrm{oc}}$ are distribution coefficients measured at the single initial concentrations $2 \mu \mathrm{M}$ for phenanthrene and $10 \mu \mathrm{M}$ for dibenzofuran. ${ }^{b}$ Values in parentheses are standard error ranges. ${ }^{c}$ Value \pm standard error.

sorption of both compounds similarly. Normalization of phenanthrene and dibenzofuran $K_{\mathrm{d}}$ values to the organic C content of the soils reduced variability between soils; however, the resulting $K_{\mathrm{d}-o c}$ values still showed considerable variability (Table 2). This supported the idea that the amount of organic $\mathrm{C}$ alone cannot account for the different sorptive properties of the soils.

\section{Sorption by soil clay fractions}

Relevant physicochemical characteristics of purified soil claysize fractions and sorption coefficients for phenanthrene and dibenzofuran are summarized in Table 4 . It should be noted that for all soils the percentage of clay-size fraction recovered was smaller than that determined in soil texture analysis (Table 1). This indicated that some clay-size particles were probably removed with larger particles during fractionation. The soil clay fractions had similar $\mathrm{pH}$, but differed largely in their organic C content (0.99-23.94\%) and clay mineralogy. Compared with the whole soils (Table 1), all clay fractions were enriched in organic C. Notably large was the organic C content of the clay fraction of the Borris soil (nearly $24 \%$ ).

Table 3 Correlation between phenanthrene and dibenzofuran $K_{\mathrm{d}}$ values and soil properties

\begin{tabular}{lcc}
\hline & \multicolumn{2}{c}{ Correlation coefficient $(r)$} \\
\cline { 2 - 3 } Soil property & Phenanthrene & Dibenzofuran \\
\hline Sand & 0.213 & 0.174 \\
Silt & 0.064 & 0.131 \\
Clay & -0.545 & -0.556 \\
Organic C & 0.666 & 0.655 \\
CEC & -0.733 & -0.702 \\
pH & $-0.838^{*}$ & -0.767 \\
$\mathrm{~N}_{2}$-SSA & -0.641 & -0.660 \\
EGME-SSA & -0.040 & -0.069 \\
\hline
\end{tabular}

*Statistically significant at the $P<0.05$ level.
X-ray diffraction revealed that the phyllosilicate content of the Borris soil was very small; just traces of kaolinite and illite-mica were identified. Montmorillonite and kaolinite predominated in the clay fraction of $\mathrm{P} 2$ and Kettering soils, respectively. The Askov soil had the most heterogeneous clay fraction, containing significant amounts of kaolinite, illite-mica, and montmorillonite-vermiculite displaying some resistance to swelling. Therefore, the clay fraction of the soils covered a wide range of organic $\mathrm{C}$ contents (wider than the bulk soils) and mineralogical characteristics (Table 4).

Phenanthrene and dibenzofuran distribution coefficients, $K_{\mathrm{d}}$, on soil clay fractions were strongly correlated with the organic C content $(r=0.99, P<0.01)$ and, consequently, inversely correlated with the amount of inorganic clay constituents (Table 4). In spite of this, normalization of sorption coefficients to the organic $\mathrm{C}$ content revealed smaller $K_{\mathrm{d}-\mathrm{oc}}$ values for the clay fractions containing smaller amounts of organic C (i.e. more mineral fraction). The phenanthrene $K_{\text {d-oc }}$ decreased from 21020 for the soil clay fraction containing $23.94 \%$ organic $\mathrm{C}$ (Borris) to 8590 for the soil clay fraction containing $0.99 \%$ organic C ( $\mathrm{P} 2$ soil). A similar trend was observed for dibenzofuran (Table 4). As for the whole soils, $K_{\mathrm{d}-\mathrm{oc}}$ values obtained for phenanthrene were about three times greater than those obtained for dibenzofuran. On the other hand, these $K_{\mathrm{d}-\mathrm{oc}}$ values on soil clay fractions were considerably greater than those measured on the bulk soils.

\section{Sorption by model sorbents}

Phenanthrene sorption to organic materials differed considerably depending on the source of the organic matter (Table 5). The phenanthrene $K_{\mathrm{d}-\mathrm{oc}}$ values were in the range 1340-16 070 litre $\mathrm{kg}^{-1} \mathrm{C}$, with a mean value of 9590 . Interestingly, this mean value is very close to the mean $K_{\mathrm{d} \text {-oc }}$ value of the soils (9466, Table 2) and considerably less than the mean $K_{\mathrm{d}-\mathrm{oc}}$ value of the clay fractions (14 280, Table 4). Another interesting feature of Table 5, is the considerable phenanthrene sorption by Aldrich HA (HA1) compared with soil-extracted 
Phenanthrene

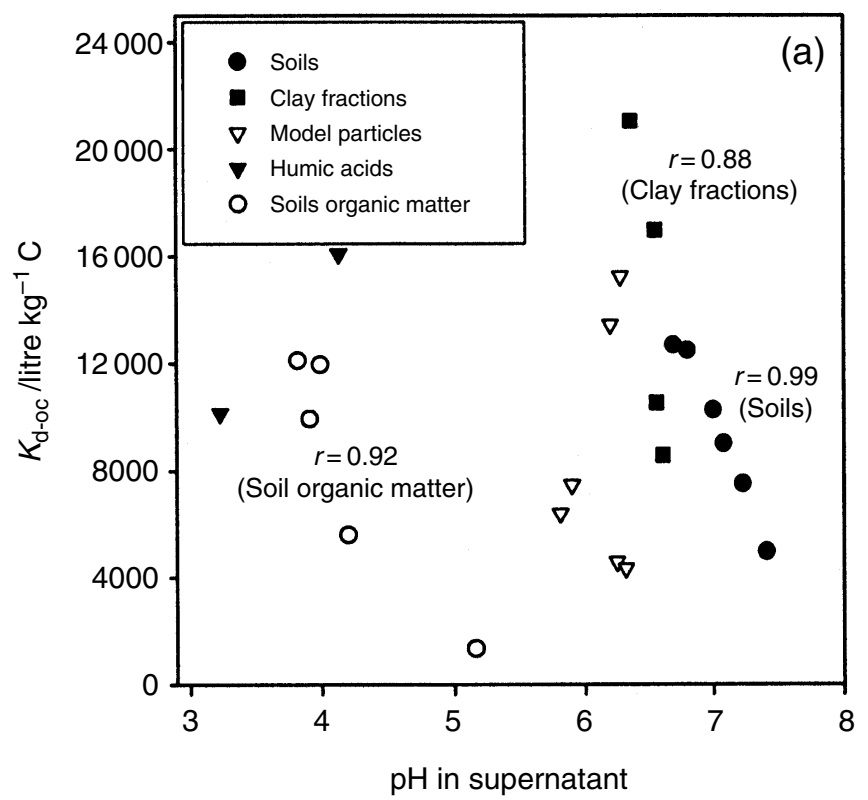

Dibenzofuran

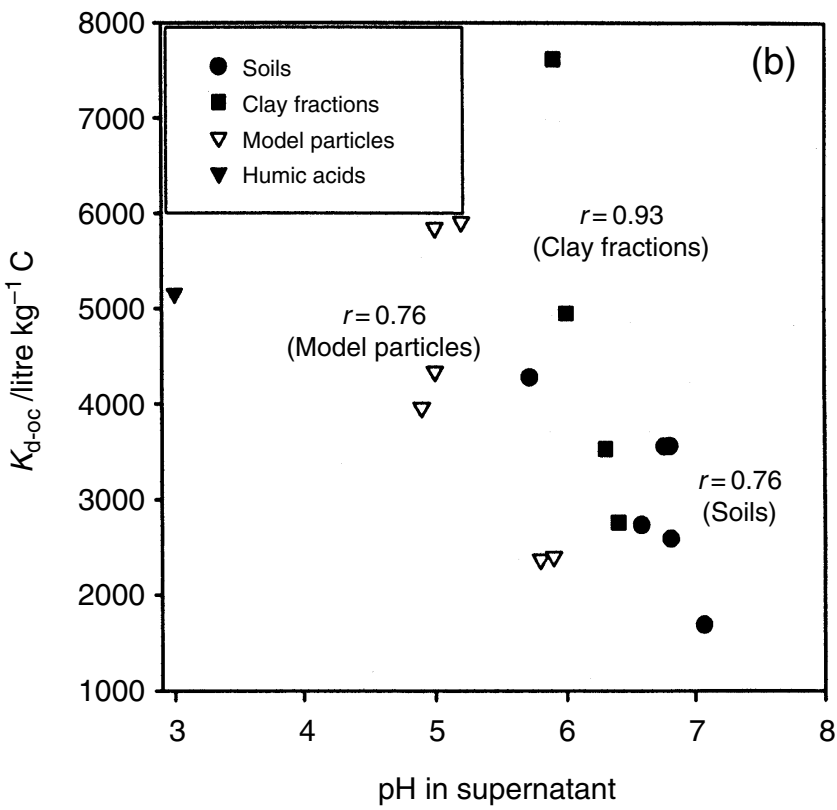

Figure $3 K_{\mathrm{d}-\mathrm{oc}}$ values against suspension pH for phenanthrene (a) and dibenzofuran (b) sorption by the different sorbents assayed.

organic materials. Similar results were found by Laor et al. (1998), who suggested that the great affinity of Aldrich humic acid for phenanthrene compared with that displayed by soilextracted organic materials could be due to its great degree of aromaticity.

Phenanthrene and dibenzofuran distribution coefficients on single, binary, and ternary model sorbents (Table 6) revealed that the affinity of the organic compounds for the three main active soil constituents decreased in the order: HA2 $>>\mathrm{SW}>$ ferrihydrite. The most interesting features of Table 6 are: (i) the sorption coefficients obtained for phenanthrene and dibenzofuran on HA2 being two orders of magnitude greater than those measured on mineral constituents (SW and ferrihydrite), and (ii) the increase in sorption caused by the presence of HA2 in binary and ternary particles. These results clearly illustrated the dominant role of SOM on the sorption of phenanthrene and dibenzofuran by the model particles. Meanwhile, dibenzofuran showed greater $K_{\mathrm{d}}$ values on the mineral constituents (SW and ferrihydrite) than phenanthrene, and a smaller $K_{\mathrm{d}}$ value on HA2, which can be attributed to the greater polarity of dibenzofuran, associated with the presence of an oxygen atom in its structure (Figure 1) (Chiou \& Kile, 1994; Xing, 2001). It is also worthy to note that there was a general increase in the sorption coefficients from binary to ternary organomineral particles (Table 6).

Another interesting feature in Table 6 is the small $K_{\mathrm{d} \text {-oc }}$ values calculated from the phenanthrene and dibenzofuran distribution coefficients on binary particles containing HA2 (particularly on ferrihydrite-HA2 particles) compared with those calculated for pure HA2, which suggests a reduction in the sorptive properties of HA2 after association with the minerals. In a previous paper, we found that association of HA2 with ferrihydrite resulted in substantial blockage of functional groups of HA2 responsible for sorption of heavy metals (Cruz-Guzmán et al., 2003). Similarly, a reduction in the availability of HA2 domains involved in the sorption of phenanthrene and dibenzofuran (i.e. hydrophobic regions) could have also occurred. Interestingly, this decrease in the $K_{\mathrm{d}-\mathrm{oc}}$ value was not observed in ternary particles (Table 6). We believe that in ternary particles the reduction of associated HA2 sorption ability could have been obscured by the considerable sorption by the blank $\mathrm{SW}$-ferrihydrite-HA2 $2_{0}$ sample $\left(K_{\mathrm{d}}=36\right.$ litre $\mathrm{kg}^{-1}$ for phenanthrene and 64 litre $\mathrm{kg}^{-1}$ for dibenzofuran, Table 6). The importance of using blank samples should thus be emphasized as these help to distinguish the actual association effects from other changes produced in the constituents during the synthesis of the associations (Celis et al., 1998; Cruz-Guzmán et al., 2003).

\section{Discussion}

The importance of SOM in the sorption of HOCs is well documented (Hamaker \& Thompson, 1972; Chiou \& Kile, 1994; Fall et al., 2003), and is clearly reflected in our experiments by the large $K_{\mathrm{d}}$ values measured for phenanthrene and dibenzofuran on purified soil organic materials compared with those measured on mineral model sorbents (Tables 5 and 6). The strong correlation found between the phenanthrene and dibenzofuran sorption coefficients on soil clay fractions and their organic $\mathrm{C}$ contents $(r=0.99, P<0.01)$ also indicates a primary role of organic matter in the retention of both compounds (Table 4). However, the weak relationship between the 
sorption coefficients for phenanthrene and dibenzofuran and the organic $\mathrm{C}$ content of the bulk soils (Table 3), along with the differences in $K_{\mathrm{d}-\mathrm{oc}}$ values among the soils, clay fractions, and model sorbents, are indicative that sorption cannot be predicted exclusively from the organic $\mathrm{C}$ content of the samples (Pusino et al., 1992).

One major cause for the different organic C-normalized sorption capacities of soils and sediments has been proposed to be organic matter heterogeneity (Karapanagioti et al., 2000; Xing, 2001; Huang et al., 2003). The potential effect of organic matter characteristics on the sorption properties of our soils is illustrated by the different affinities for phenanthrene displayed by organic matter samples extracted from different sources (Table 5). Also, the greater $K_{\mathrm{d}-\mathrm{oc}}$ values obtained for phenanthrene and dibenzofuran sorption on the soil clay fractions (Table 4) compared with those measured on the corresponding bulk soils (Table 2) could indicate that organic matter with great affinity for the organic compounds accumulated in the clay-size fraction of the soils. Similar differences between $K_{\text {oc }}$ values of bulk soils and their clay-size fractions were found by Carmo et al. (2000) for naphthalene and phenanthrene, and interpreted in terms of organic matter heterogeneity between different particle-size fractions.

Along with the influence of organic matter characteristics, the inverse relationship between phenanthrene and dibenzofuran sorption and the clay content of the soils should also be noted (Table 3). Greater amounts of inorganic constituents in the clay-size fraction of the soils were also accompanied by smaller $K_{\mathrm{d}-\mathrm{oc}}$ values (Table 4 ). These results strongly suggest a negative effect of clay inorganic constituents on the ability of SOM to sorb phenanthrene and dibenzofuran.

Clay inorganic constituents can influence sorption of organic compounds by two principal mechanisms: (i) by enlarging the contribution of the soil mineral fraction in the retention process (Karickhoff, 1984; Onken \& Traina, 1997; Broholm et al., 1999), and (ii) by influencing the sorptive properties of organic matter as a result of mutual interactions that affect organic matter accessibility, sorptivity or both (Pusino et al., 1992; Njoroge et al., 1998; Jones \& Tiller, 1999). Our results with model sorbents showed that although phenanthrene and dibenzofuran displayed some affinity for mineral constituents such as montmorillonite and ferrihydrite, $K_{\mathrm{d}}$ values were two orders of magnitude smaller than those measured on HA2 (Table 6). Consequently, the role of these minerals in sorption of phenanthrene and dibenzofuran is expected to be equal to that of HA2 in systems with HA2:mineral ratios about 1:100. This result is consistent with the estimation of Green \& Karickhoff (1990) that large, nonpolar organic molecules $\left(>\mathrm{C}_{10}\right)$ have typically more than 100 times greater affinity for soil organic $\mathrm{C}$ than for soil minerals, which makes the role of soil minerals in sorption insignificant in most surface soils. We believe that, except for P2 soil (clay:organic $\mathrm{C}$ ratio $=36$ ), it is unlikely that mineral constituents contributed directly to the sorption of phenanthrene and 
Phenanthrene

\begin{tabular}{|c|c|c|c|c|}
\hline \multirow[b]{2}{*}{ Sorbent } & \multirow[b]{2}{*}{$\begin{array}{l}\text { Organic C } \\
\qquad / \%\end{array}$} & \\
\hline & & $\mathrm{pH}$ & $K_{\mathrm{d}} \quad /$ litre $\mathrm{kg}^{-1}$ & $K_{\mathrm{d}-\mathrm{oc}}$ \\
\hline HA1 (commercial humic acid) & 56.5 & 4.1 & $9080 \pm 833^{\mathrm{a}}$ & 16070 \\
\hline HA2 (soil humic acid) & 52.9 & 3.2 & $5363 \pm 234$ & 10140 \\
\hline $\mathrm{B}_{\mathrm{hs}}($ soil organic matter) & 61.4 & 5.2 & $821 \pm 81$ & 1340 \\
\hline $\mathrm{O}_{\mathrm{h}} \mathrm{S}$ (soil organic matter) & 54.1 & 4.2 & $3027 \pm 433$ & 5590 \\
\hline $\mathrm{O}_{\mathrm{h}} \mathrm{F}$ (soil organic matter) & 55.3 & 4.0 & $6611 \pm 470$ & 11950 \\
\hline $\mathrm{O}_{\mathrm{h}} \mathrm{P}$ (soil organic matter) & 59.5 & 3.8 & $7203 \pm 2267$ & 12100 \\
\hline $\mathrm{H}$ (peat) & 56.4 & 3.9 & $5601 \pm 1161$ & 9930 \\
\hline
\end{tabular}

${ }^{\mathrm{a}}$ Mean \pm standard error.

dibenzofuran by sorbing extensive amounts of the chemicals. This is supported by the fact that, while contribution of soil minerals to the sorption process is generally accompanied by an increase in $K_{\text {oc }}$ value, greater amounts of clay inorganic constituents in our soils and clay fractions were generally associated with smaller $K_{\mathrm{d}-\mathrm{oc}}$ values for phenanthrene and dibenzofuran (Tables 2 and 4). The only exception was dibenzofuran sorption by the clay fraction of the P2 soil (Table 4), where a small contribution of smectitic clay minerals could have occurred.

Despite the direct contribution of mineral constituents to sorption of phenanthrene and dibenzofuran in our soils being likely to be small, it is well known that clay inorganic constituents play a major role in binding SOM, and it has been proposed that mineral-bound organic material is less accessible for the incorporation of HOCs than free organic material (Pusino et al., 1992; Jones \& Tiller, 1999). Hence, clay inorganic constituents could have indirectly affected the sorption properties of our soils by reducing the availability of SOM for phenanthrene and dibenzofuran sorption. This effect is clearly illustrated in the binary model particles by the smaller $K_{\mathrm{d}-\mathrm{oc}}$ values obtained for phenanthrene and dibenzofuran sorption on SW- and ferrihydrite-associated HA2 compared with those obtained on HA2 (Table 6). Indeed, the large $K_{\mathrm{d}-\mathrm{oc}}$ values

Table 6 Phenanthrene and dibenzofuran sorption coefficients on single, binary, and ternary model particles

\begin{tabular}{|c|c|c|c|c|c|c|c|c|c|c|}
\hline \multirow[b]{2}{*}{ Sorbent } & \multicolumn{3}{|c|}{ Sorbent composition ${ }^{\mathrm{a}}$} & \multirow[b]{2}{*}{$\begin{array}{c}\mathrm{f}_{\mathrm{oc}}^{\mathrm{b}} \\
/ \mathrm{g} \mathrm{g}^{-1}\end{array}$} & \multicolumn{3}{|c|}{ Phenanthrene } & \multicolumn{3}{|c|}{ Dibenzofuran } \\
\hline & SW & $\begin{array}{l}\text { Ferrih } \\
-/ \%\end{array}$ & HA2 & & $\mathrm{pH}$ & $\begin{array}{c}K_{\mathrm{d}} \\
\quad / \text { litre } \mathrm{kg}^{-1}\end{array}$ & $K_{\mathrm{d}-\mathrm{oc}}$ & $\mathrm{pH}$ & $\begin{array}{c}K_{\mathrm{d}} \\
-/ \text { litre } \mathrm{kg}^{-1}\end{array}$ & $\underline{K_{\mathrm{d}-\mathrm{oc}}}$ \\
\hline \multicolumn{11}{|l|}{ Single sorbents } \\
\hline SW & 100 & 0 & 0 & 0 & 6.4 & $2 \pm 5^{\mathrm{c}}$ & - & 6.7 & $14 \pm 6^{\mathrm{c}}$ & - \\
\hline Ferrih & 0 & 100 & 0 & 0 & 5.7 & $<1$ & - & 5.9 & $4 \pm 4$ & - \\
\hline HA2 & 0 & 0 & 100 & 0.529 & 3.2 & $5363 \pm 234$ & 10140 & 3.0 & $2731 \pm 224$ & 5160 \\
\hline \multicolumn{11}{|l|}{ Binary associations } \\
\hline SW-Ferrih (blank) & 100 & 0 & 0 & 0 & 6.1 & $30 \pm 4$ & - & 5.7 & $114 \pm 16$ & - \\
\hline SW-Ferrih $_{8}$ & 92.7 & 7.3 & 0 & 0 & 5.6 & $12 \pm 11$ & - & 4.6 & $55 \pm 8$ & - \\
\hline SW-Ferrih $_{16}$ & 86.3 & 13.7 & 0 & 0 & 5.3 & $19 \pm 6$ & - & 4.5 & $56 \pm 14$ & - \\
\hline SW-HA2 ${ }_{0}$ (blank) & 100 & 0 & 0 & 0 & 6.5 & $20 \pm 4$ & - & 5.7 & $19 \pm 2$ & - \\
\hline SW-HA2 ${ }_{4}$ & 95.7 & 0 & 4.3 & 0.0226 & 5.9 & $153 \pm 4$ & 6770 & 5.0 & $98 \pm 9$ & 4340 \\
\hline SW-HA $2_{8}$ & 93.3 & 0 & 6.7 & 0.0354 & 5.8 & $226 \pm 1$ & 6380 & 4.9 & $140 \pm 15$ & 3960 \\
\hline Ferrih-HA $2_{0}$ (blank) & 0 & 100 & 0 & 0 & 6.5 & $<1$ & - & 6.1 & $4 \pm 4$ & - \\
\hline Ferrih-HA2 $2_{4}$ & 0 & 96.3 & 3.7 & 0.0198 & 6.3 & $90 \pm 9$ & 4550 & 5.8 & $47 \pm 8$ & 2370 \\
\hline Ferrih-HA2 $2_{8}$ & 0 & 93.1 & 6.9 & 0.0366 & 6.3 & $158 \pm 8$ & 4320 & 5.9 & $88 \pm 4$ & 2400 \\
\hline \multicolumn{11}{|l|}{ Ternary associations } \\
\hline SW-Ferrih-HA2 $2_{0}$ (blank) & 85.2 & 14.8 & 0 & 0 & 6.0 & $36 \pm 8$ & - & 4.8 & $64 \pm 14$ & - \\
\hline SW-Ferrih-HA2 $2_{4}$ & 82.5 & 14.6 & 2.9 & 0.0154 & 6.3 & $234 \pm 9$ & 15190 & 5.2 & $91 \pm 7$ & 5910 \\
\hline SW-Ferrih-HA $2_{8}$ & 81.0 & 13.5 & 5.5 & 0.0294 & 6.2 & $395 \pm 12$ & 13440 & 5.0 & $172 \pm 35$ & 5850 \\
\hline
\end{tabular}

${ }^{\mathrm{a}} \mathrm{SW}$, Wyoming montmorillonite; Ferrih, ferrihydrite; HA2, soil humic acid. ${ }^{\mathrm{b}} \mathrm{f}_{\mathrm{oc}}$, organic C fraction. ${ }^{\mathrm{c}}$ Mean \pm standard error. 


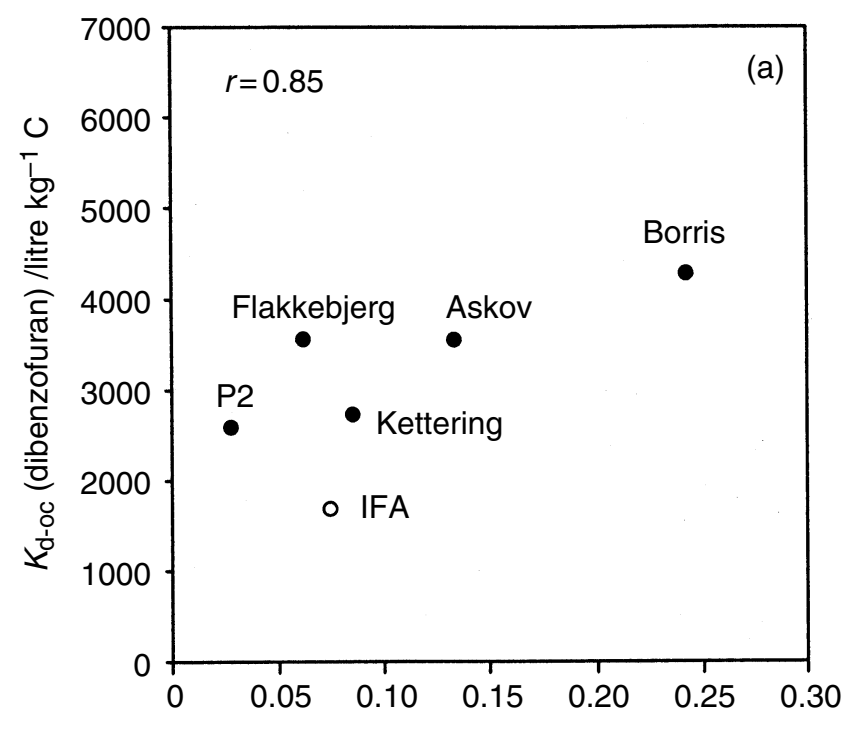

high association low association

Organic C/clay ratio

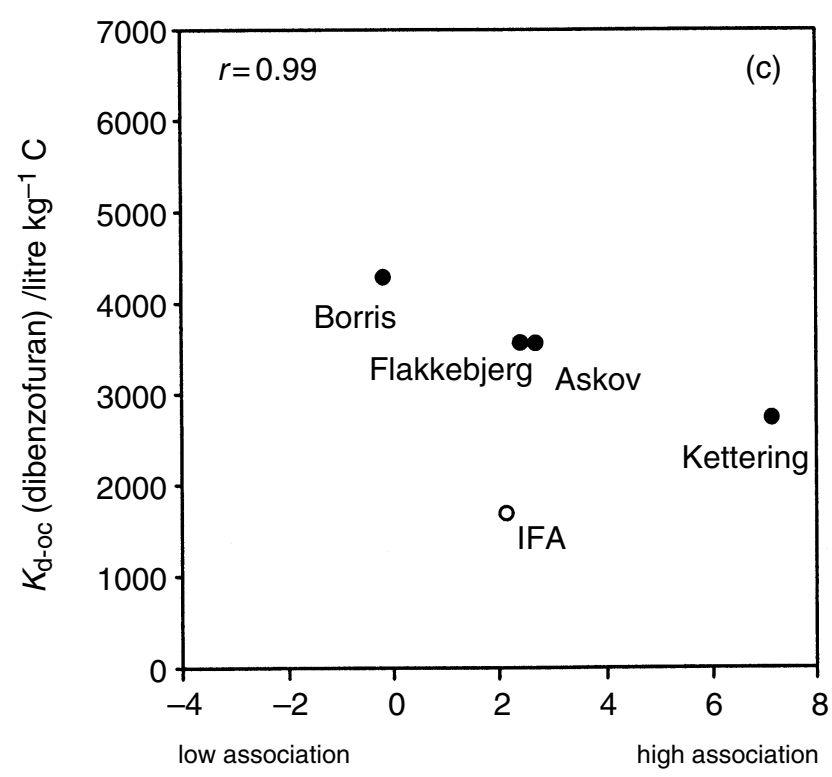

$\Delta \mathrm{N}_{2}-\mathrm{SSA} / \mathrm{OC}$

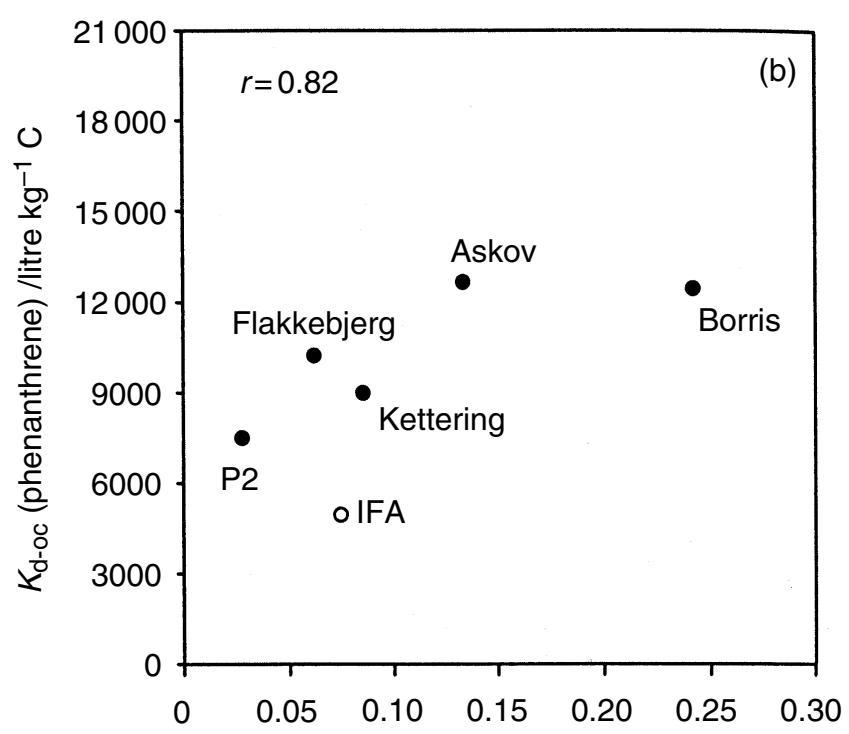

high association low association

Organic C/clay ratio

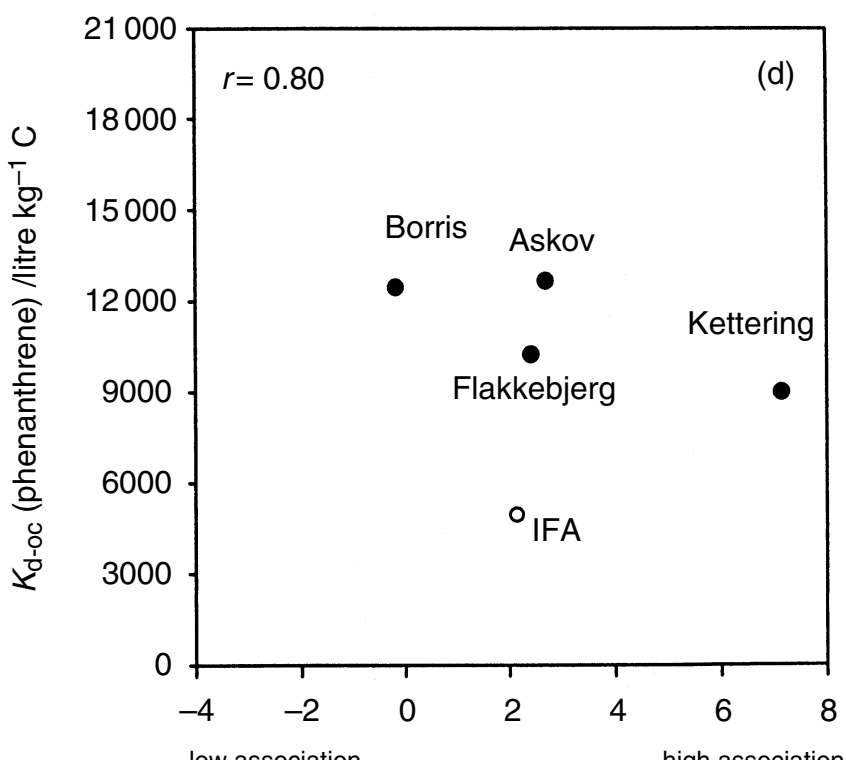

low association

high association

$\Delta \mathrm{N}_{2}-\mathrm{SSA} / \mathrm{OC}$

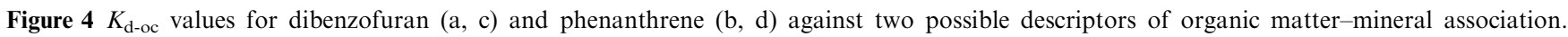
Association is assumed to increase with $\Delta \mathrm{N}_{2}$-SSA/OC and to decrease with the organic C/clay ratio.

measured for soils with particularly small clay contents, such as Borris or Askov (Table 2), and also for soil clay fractions rich in organic C (Table 4), strongly suggest that clay-free SOM is more sorptive than SOM associated with clay. Another indirect effect that deserves to be noted is the increase of $\mathrm{pH}$ with increasing clay content in natural soils (Table 1). With increasing $\mathrm{pH}$, acidic functional groups of organic matter become negatively charged, and the increasing polarity of
SOM is expected to reduce its affinity for non-polar compounds (Laor et al., 1998). Indeed, phenanthrene and dibenzofuran sorption on soils was strongly negatively correlated to soil $\mathrm{pH}$ (Table 3). Although the intercorrelation between $\mathrm{pH}$ and clay content makes it difficult to separate the effects of these two variables, interestingly, an increase in $K_{\mathrm{d}-\mathrm{oc}}$ values with decreasing $\mathrm{pH}$ was also observed for many other groups of sorbents assayed (Figure 3). A similar decrease in 
phenanthrene sorption with increasing $\mathrm{pH}$ was observed by Laor et al. (1998) for mineral-associated humic acid samples.

In an attempt to represent organic matter-mineral association in the soils studied, the $K_{\mathrm{d}-\mathrm{oc}}$ values obtained for our soils were plotted against two potentially useful descriptors of this association (Figure 4): (i) the organic $\mathrm{C} /$ clay ratio, and (ii) the increase in the $\mathrm{N}_{2}$-SSA of the soils after removal of SOM by calcination at $350^{\circ} \mathrm{C}$ (Mayer \& Xing, 2001; Kaiser \& Guggenberger, 2003). The first descriptor was the simplest and assumes greater association in soils with smaller organic $\mathrm{C} /$ clay ratios. The second descriptor assumes that the increase in $\mathrm{N}_{2}$-SSA $\left(\Delta \mathrm{N}_{2}\right.$-SSA) after removal of SOM by calcination corresponds to mineral surfaces that were originally coated by organic material (Mayer \& Xing, 2001). We considered this increase in $\mathrm{N}_{2}$-SSA, normalized to the organic $\mathrm{C}$ content of the soil $\left(\Delta \mathrm{N}_{2}-\mathrm{SSA} / \mathrm{OC}\right)$, to be a measure of the fraction of organic matter associated with soil minerals. Except for the IFA soil, whose $K_{\mathrm{d} \text {-oc }}$ was considerably smaller than expected from its organic C/clay and $\Delta \mathrm{N}_{2}$-SSA/OC values, quite consistent relationships were found between both descriptors and the $K_{\mathrm{d}-o c}$ values measured for phenanthrene and dibenzofuran sorption by the soils (Figure 4). The particularly small $K_{\mathrm{d}-\text { oc }}$ value measured for IFA soil may be related to its high $\mathrm{pH}$, which probably resulted from its carbonate content (Table 1). Besides their effect on soil $\mathrm{pH}$, carbonates are known to play an important role in binding soil organic matter, which might have further contributed to reduce the sorptivity of the organic matter of IFA soil. In summary, the data presented strongly suggest that clay contributed negatively to the sorptive properties of the SOM for phenanthrene and dibenzofuran, most likely through domain blockage arising from organic matterclay interactions and associated $\mathrm{pH}$ shifts.

\section{Conclusions}

Achieving a better understanding of the factors influencing the sorptivity of SOM and the variability of the parameter $K_{\mathrm{oc}}$ is considered important in improving predictions of sorption of HOCs in soils. The sorption behaviour of phenanthrene and dibenzofuran on six natural soils, their clay-size fractions, and a series of single, binary, and ternary model sorbents indicated that organic matter heterogeneity and domain blockage through organic matter-mineral interactions are two important factors influencing the sorptive properties of SOM for the HOCs. In the soils studied, with organic $\mathrm{C}$ and clay contents typical of agricultural soils, it appeared that clay had a negative effect on the sorption of phenanthrene and dibenzofuran through a combination of organic matter domain blockage and associated $\mathrm{pH}$ shifts. We illustrated that the development of suitable descriptors for the extent of organic matter-mineral interactions could help to improve current $K_{\mathrm{oc}}$-based sorption predictions and subsequently the assessment of risk associated with the presence and transport of HOCs in soil.

\section{Acknowledgements}

This work was financed by the FP5 EU Project 'Development of a Decision Support System for Sustainable Management of Contaminated Land by Linking Bioavailability, Ecological Risk, and Ground Water Pollution of Organic Pollutants' (EVK1-CT-2001-00105) (http://www.liberation.dk).

\section{References}

Ahmad, R., Kookana, R.S., Alston, A.M. \& Skjemstad, J.O. 2001. The nature of soil organic matter affects sorption of pesticides. 1. Relationships with carbon chemistry as determined by ${ }^{13} \mathrm{C}$ PMAS NMR spectroscopy. Environmental Science and Technology, 35, 878-889.

Broholm, M.M., Broholm, K. \& Arvin, E. 1999. Sorption of heterocyclic compounds on natural clayey till. Journal of Contaminant Hydrology, 39, 183-200.

Brown, G. 1961. The X-ray Identification and Crystal Structures of Clay Minerals. Mineral Society, London.

Carmo, A.M., Hundal, L.S. \& Thompson, M.L. 2000. Sorption of hydrophobic organic compounds by soil materials: application of unit equivalent Freundlich coefficients. Environmental Science and Technology, 34, 4363-4369.

Celis, R., Cornejo, J., Hermosín, M.C. \& Koskinen, W.C. 1997. Sorption-desorption of atrazine and simazine by model soil colloidal components. Soil Science Society of America Journal, 61, 436-443.

Celis, R., Cornejo, J., Hermosín, M.C. \& Koskinen, W.C. 1998. Sorption of atrazine and simazine by model associations of soil colloids. Soil Science Society of America Journal, 62, 165-171.

Chiou, C.T. \& Kile, D.E. 1994. Effects of polar and nonpolar groups on the solubility of organic compounds in soil organic matter. Environmental Science and Technology, 28, 1139-1144.

Chiou, C.T., Peters, L.J. \& Freed, V.H. 1979. A physical concept of soil-water equilibria for nonionic organic compounds. Science, 206, 831-832.

Cihacek, L.J. \& Bremner, J.M. 1979. A simplified ethylene glycol monoethyl ether procedure for assessment of soil surface area. Soil Science Society of America Journal, 43, 821-822.

Cruz-Guzmán, M., Celis, R., Hermosín, M.C., Leone, P., Nègre, M. \& Cornejo, J. 2003. Sorption-desorption of lead(II) and mercury(II) by model associations of soil colloids. Soil Science Society of America Journal, 67, 1378-1387.

Fall, C., Chaouki, J., Chavarie, C. \& Elena-Ortega, R. 2003. Multivariate study on phenanthrene sorption in soils. Journal of Environmental Engineering-ASCE, 129, 1030-1040.

Gee, G.W. \& Bauder, J.W. 1982. Particle-size analysis. In: Methods of Soil Analysis: Part 1, Physical and Mineralogical Methods, 2nd edn (ed. A. Klute), pp. 383-411. Agronomy Monograph No 9, American Society of Agronomy and Soil Science Society of America, Madison, WI.

Giles, C.H., McEwan, J.H., Nakwa, S.N. \& Smith, D. 1960. Studies in adsorption. Part XI. A system of classification of solution adsorption isotherms, and its use in diagnosis of adsorption mechanisms and in measurement of specific surface areas of solids. Journal of the Chemical Society, 3, 3973-3993.

Green, R.E. \& Karickhoff, S.W. 1990. Sorption estimates for modeling. In: Pesticides in the Soil Environment: Processes, Impact, and 
Modeling (ed. H.H. Cheng), pp. 79-101. Book Series No 2, Soil Science Society of America, Madison, WI.

Hamaker, J.W. \& Thompson, J.M. 1972. Adsorption. In: Organic Chemicals in the Soil Environment, Volume 1 (eds C.A.I. Goring \& J.W. Hamaker), pp. 49-143. Marcel Dekker, New York.

Huang, W., Peng, P., Yu, Z. \& Fu, J. 2003. Effects of organic matter heterogeneity on sorption and desorption of organic compounds by soils and sediments. Applied Geochemistry, 18, 955-972.

Hundal, L.S., Thompson, M.L., Laird, D.A. \& Carmo, A.M. 2001. Sorption of phenanthrene by reference smectites. Environmental Science and Technology, 35, 3456-3461.

Jackson, M.L. 1975. Soil Chemical Analysis: Advanced Course. M.L. Jackson, Madison, WI.

Jones, K.D. \& Tiller, C.L. 1999. Effect of solution chemistry on the extent of binding of phenanthrene by a soil humic acid: a comparison of dissolved and clay bound humic. Environmental Science and Technology, 33, 580-587.

Kaiser, K. \& Guggenberger, G. 2003. Mineral surfaces and soil organic matter. European Journal of Soil Science, 54, 219-236.

Karapanagioti, H.K., Kleineidam, S., Sabatini, D.A., Grathwohl, P. \& Ligouis, B. 2000. Impacts of heterogeneous organic matter on phenanthrene sorption: equilibrium and kinetic studies with aquifer material. Environmental Science and Technology, 34, 406-414.

Karickhoff, S.W. 1984. Organic pollutant sorption in aquatic systems. Journal of Hydraulic Engineering, 110, 707-735.

Laor, Y., Farmer, W.J., Aochi, Y. \& Strom, P. 1998. Phenanthrene binding and sorption to dissolved and to mineral-associated humic acid. Water Research, 32, 1923-1931.
Mayer, L.M. \& Xing, B. 2001. Organic matter-surface area relationships in acid soils. Soil Science Society of America Journal, 65, 250-258.

Njoroge, B.N.K., Ball, W.P. \& Cherry, R.S. 1998. Sorption of 1,2,4-trichlorobenzene and tetrachloroethene within an authigenic soil profile: changes in $K_{\mathrm{oc}}$ with soil depth. Journal of Contaminant Hydrology, 29, 347-377.

Onken, B.M. \& Traina, S.J. 1997. The sorption of pyrene and anthracene to humic acid-mineral complexes: effect of fractional organic carbon content. Journal of Environmental Quality, 26, 126-132.

Pusino, A., Liu, W. \& Gessa, C. 1992. Influence of organic matter and its clay complexes on metolachlor adsorption on soil. Pesticide Science, 36, 283-286.

Rhoades, J.D. 1982. Cation exchange capacity. In: Methods of Soil Analysis: Part 2, Chemical and Microbiological Properties, 2nd edn (eds A.L. Page, R.H. Miller \& D.R. Keeney), pp. 149-151. Agronomy Monograph No 9, American Society of Agronomy and Soil Science Society of America, Madison, WI.

Schlautman, M.A. \& Morgan, J. 1993. Effects of aqueous chemistry on the binding of polycyclic aromatic-hydrocarbons by dissolved humic materials. Environmental Science and Technology, 27, 961-969.

Tabatabai, M.A. \& Bremner, J.M. 1970. Use of the Leco automatic 70-record carbonanalyzer for total carbon analysis of soils. Soil Science Society of America Proceedings, 24, 608-610.

Wauchope, R.D., Yeh, S., Linders, J.B.H.J., Kloskowski, R., Tanaka, K., Rubin, B. et al. 2002. Pesticide soil sorption parameters: theory, measurement, uses, limitations and reliability. Pest Management Science, 58, 419-445.

Xing, B. 2001. Sorption of naphthalene and phenanthrene by soil humic acids. Environmental Pollution, 111, 303-309. 